\title{
A novel fluid-feeding mechanism for microbivory in the Acariformes (Arachnida: Acari)
}

\author{
Samuel J. Bolton ${ }^{\mathrm{a}}$, Gary R. Bauchan ${ }^{\mathrm{b}}$, Ronald Ochoa ${ }^{\mathrm{c}}$ and Hans Klompen ${ }^{\mathrm{a}}$
}

${ }^{a}$ Acarology Laboratory, Department of Evolution, Ecology and Organismal Biology, The Ohio State University, 1315 Kinnear Rd., Columbus, OH 43212, USA; ${ }^{b}$ Electron and Confocal Microscopy Unit, USDA, ARS, BARC-West, Bldg. 012, 10300 Baltimore Ave., Beltsville, MD 20705-2350, USA; 'Systematic Entomology Laboratory, USDA, ARS, BARC-West, Bldg. 005, 10300 Baltimore Ave., Beltsville, MD 20705-2350, USA.

Low temperature scanning electron microscopy (LT-SEM) has revealed anatomical details suggesting that Osperalycus and Gordialycus (Acariformes: Nematalycidae) have an unusual feeding apparatus that is hypothesized to be specialized for feeding on the fluid contents of small microorganisms (diameter $<5 \mu \mathrm{m}$ ). Both mite genera have a feeding strategy that appears to involve picking up small microorganisms and placing them onto the subcapitulum for puncturing. However, they have slightly different variants of the same basic rupturing mechanism. Whereas Gordialycus has evolved expansive and convergent rutella to hold the microorganisms in place while pushing chelicerae into them, Osperalycus has evolved a pouch into which a microorganism is inserted. The rutella reinforce this pouch while the chelicerae break up the microorganism. Both types of mouthpart apparatus seem to be adapted to minimize waste, an appropriate specialization given the organically impoverished habitats in which these mites live.

Keywords: Nematalycidae, Osperalycus, Gordialycus, LT-SEM, gnathosoma, rutellum, microorganism

\section{Introduction}

Fluid-feeding clearly predominates within the Arachnida; only the Opiliones, some Solifugae and some Acari feed on solids (Muma 1966, Walter, 1988; Hillyard and Sankey, 1989; Walter and Proctor, 1998; Acosta and Machado, 2007; Heethoff and Norton, 2009). Whereas a large number of species of fluid feeding Acariformes have piercing-sucking mouthparts, in which the chelicerae are usually highly modified (Krantz and Lindquist, 1979; Di Palma et al., 2009; Beard et al., 2012; Krenn and Aspöck, 2012), most other arachnids use chelate chelicerae to macerate their prey for the extraction of fluids. This is often accompanied by extra-oral digestion in which enzymes are introduced into the food (Cohen, 1995, 1998). Other fluidfeeding adaptations have arisen in association with chelate chelicerae. For example, the Mesostigmata (Parasitiformes) use a specialized structure - the tritosternum - to prevent loss of fluid after opening up a prey item with their chelicerae (Wernz and Krantz, 1976).

Although the majority of fluid-feeding arachnids feed on other animals or, more rarely, vascular plants, many species of mites are small enough to be able to extract the fluid contents of

${ }^{*}$ Corresponding author. Email: samuel.bolton77@googlemail.com 
microorganisms such as protists and fungi. Some mites within the Mesostigmata appear to have specially adapted chelate chelicerae for squeezing the liquid contents out of mycelial masses and into their prebuccal cavity (Walter and Lindquist, 1989), and some species of Prostigmata have fine enough stylet-like chelicerae to pierce the hyphae of fungi (Kaliszewski et al., 1995). The Nanorchestidae (Endeostigmata) have evolved a fine labral process beneaththe chelicerae, which has been hypothesized to act as a piercing structure for feeding on the fluid contents of algae (Krantz and Lindquist, 1979).

Although these feeding mechanisms are suitable for some of the larger microorganisms, they may be of little use for very small single-celled eukaryotes and prokaryotes $(<10 \mu \mathrm{m})$. The chelate chelicerae of many mites are likely to be too messy and inefficient for dealing with such a low volume of fluid, and would require a large aggregation of the food items in order to adequately process them. Microorganisms also present a problem for piercing-sucking mouthparts; the mouthparts may be too broad, crushing instead of piercing the organism, or too long, penetrating all the way through the organism. It would also be challenging for a mite to accurately direct a stylet-like structure into such a small target.

The Nematalycidae (Acariformes: Endeostigmata) is a family of vermiform mites (Fig. 1) that includes five monospecific genera that inhabit mineral soil or sand (Strenzke, 1954; Cunliffe, 1956; Coineau et al., 1967; Schubart, 1973; Bolton et al., 2014). A minute mouth opening and a very narrow esophagus suggests that this family feeds exclusively on fluids (; Haupt and Coineau, 1999; pers. obs.). However, it is not known what specific types of food the Nematalycidae feed on. Distinct differences in the morphology of the mouthparts between genera indicate that diet is likely to vary across the family. With the aid of low-temperature scanning electron microscopy (LT-SEM), we demonstrate that Osperalycus and Gordialycus (Acariformes: Nematalycidae) have unusual mouthparts that appear to be adapted for feeding on the fluid contents of small microorganisms $(<5 \mu \mathrm{m})$.

\section{Method}

LT-SEM was undertaken at the US Department of Agriculture, Electron \& Confocal Microscopy Unit, Beltsville, MD. Most species of Nematalycidae were collected via soil washing in accordance with Kethley (1991). This meant having to mount specimens that had been kept in alcohol (80\% or 95\%). However, live specimens of Osperalycus tenerphagus Bolton \& Klompen were collected and mounted for LT-SEM by directly removing them from floated material that had not yet been sieved. This was accomplished by placing the floated material directly under a dissection microscope (see also Bolton et al., 2015).

Five different species were collected and observed in an LT-SEM: Gordialycus sp. A (absence of lateral claws) \& B (two lateral claws on legs I, II and III), Osperalycus tenerphagus Bolton \& Klompen, cf. Psammolycus n. sp. and Cunliffea strenzkei Cunliffe. The mites were collected from four different locations across the USA (Appendix A). Osperalycus tenerphagus was collected from a silty clay loam in Columbus, Ohio. All of the other species were collected from sands. Voucher specimens of all taxa are deposited at the Ohio State University Acarology Collection. Specimens were prepared for LT-SEM using the same techniques as described in Bolton et al. (2014).

Measurements were based on LT-SEM images of multiple specimens. It was not always possible to distinguish nymphs and adults, especially for Gordialycus. Therefore, mean values

for sizes of mouthpart structures almost certainly included specimens from different 
developmental stages (excluding the readily recognizable stages of larva and pre-larva). However, there is very little growth in the mouthparts from the larval to adult stage. Light microscope measurements, where developmental stages could be confidently determined, showed that the size of the chelicerae and palps increased by less than $10 \%$ in Osperalycus, and less than $20 \%$ in Gordialycus from larva to adult (Appendix B).

\section{Morphology of mouthparts}

\subsection{General mouthpart structure and function.}

The Nematalycidae have a mouthpart plan that is similar to that of other mites in the Endeostigmata - the chelicerae are chelate and the subcapitulum, which is a ventral structure formed from the fusion of the palp coxae, includes a pair of lateral lips (subcapitular extensions) and rutella (sclerotized structures that project from the lateral lips) (Fig. 2a). The rutella have been considered to be absent in the Nematalycidae (Walter, 2009). However, they are present but minute (Kethley, 1990; Bolton et al., 2014; Bolton et al., in preparation). The function of the rutella is to facilitate the manipulation and ingestion of foods (Alberti, 2008). The diversity of shapes that have been found in these structures appears to be associated with different feeding methods (Akimov, 1979; Alberti and Coons, 1999). In the majority of cases they are associated with particulate feeding, where they appear to be used to break up food particles that are being pulled into the preoral channel by the chelicerae (Grandjean, 1957; Dinsdale, 1974; Théron, 1979; Evans, 1992).

The general structure of the mouthparts of the Nematalycidae is quite compact (Fig. 2a). In common with almost all other mites, this family lacks a labium. The lateral lips tend to be tightly adjoined, forming a single structure (Fig. 2a); a suture runs between them. The labrum is usually long and narrow. It lies over the surface of the lateral lips, creating a tight channel that leads into a small mouth at the base of the labrum.

The number of palp segments varies between genera (1 to 4 segments). There is also considerable intergeneric variation in the length of the chelicerae and cheliceral digits, and in the form of the rutella and lateral lips.

Each chelicera comprises a trochanter, a shaft and two digits (Fig. 2b, c) - the fixed digit and the movable digit (the term 'digit' is treated here as a synonym of 'chela', i.e. it excludes the large cheliceral shaft). The fixed digit is a dorsal extension of the cheliceral shaft. The movable digit articulates against the fixed digit, allowing the chelicerae to "grab" or break up food items.

\subsection{Osperalycus}

LT-SEM revealed that the anterior region of the lateral lips has been modified into a small pouch (Fig. 3a, b). The pouch is $5 \frac{1}{2} \mu \mathrm{m}$ wide at the rim, although the internal width is only $4 \mu \mathrm{m}$ due to the thickness of the wall. The wall of the pouch is composed of smooth or non-striated integument. Non-striated integument also makes up some of the venter of the gnathosoma (Fig. 4c). The dorsal surface of the pouch appears to be composed of several overlapping integumental sheets or leaves (Fig. 3b). We do not know how each of these leaves correspond with each of the two lateral lips. The leaves appear to represent flap-like dorsal extensions of the lateral lips,

although their developmental origin is far from clear. The venter of the pouch is simpler and 
reveals a single suture between the lateral lips (Fig. 4c), which runs posteriorly from where the rutella overlap at the midline. . The pouch is invisible under a light microscope due to low levels of sclerotization. The much darker and more sclerotized rutella are convergent and are pressed up firmly against the outside of the pouch (Fig. 4a, b). The labrum is relatively long and narrow, projecting into the pouch at an angle that is nearly horizontal (Fig. 4b). Consequently, the preoral cavity (the channel lying between the labrum and the lateral lips) runs from the inside of the pouch into the mouth. The pouch therefore forms a separate and additional cavity that contains the terminus of the preoral cavity.

The chelicerae are short $(\sim 12 \mu \mathrm{m})$, each with a single seta located on the dorsum of the shaft, proximal to the fixed digit. When the chelicerae are extended forwards, the dorsoventrally narrow digits completely slot into the pouch (Fig. 3a). Whereas the fixed digits are pressed together above the labrum when the chelicerae are slotted into the pouch (Fig. 4a), the movable digits slant outwards and away from one another in order to slot in on either side of the labrum.

The chelicerae are slanted downwards into the pouch - the dorsal views of the chelicerae and pouch (Fig. 3; 4) would therefore be anterodorsal with respect to the main body if the main body was in the field of view.

The rutella are pressed up against the outside of the pouch. The bases of the rutella are broad and intrude into the sides of the pouch. This produces a narrow slot inside the pouch, between the bases, into which the digits neatly fit when they are extended (Fig. 4a, c). The rutellum distally narrows into a dorsoventrally deep digit that lies firmly against the front of the pouch. The tips of both digits are flanged and clearly overlap one another, buttressing the anterior corner of the pouch at the midline (Fig. 4c; 6a).

The palps are short $(\sim 10 \mu \mathrm{m})$ and three-segmented, tentatively designated femur, genu and tarsus (Bolton et al., 2014). Each of the palps bear six setae on the tarsus (three ventral, two dorsal and one anterior) and a single dorsal seta on the genu. The anterior/distal seta, on the palp tarsus, has a tip that has been modified into a shallow cup-like or concave structure (Fig. 5a). The cup has a diameter of $0.8 \mu \mathrm{m}$. The length and minimal thickness of the stem is 1.5 and $0.3 \mu \mathrm{m}$, respectively. There are two very short cuticular protuberances at the base of this modified seta (Fig. 5a: Cp). A similarly shaped protuberance is also present on the dorsum of the palp tarsus. Four of the five other setae on the palp tarsus have tips that reach near to the modified seta (Fig $5 b)$.

\subsection{Gordialycus}

As with Osperalycus, the lateral lips of both species of Gordialycus tightly adjoin. But instead of forming a pouch, they are shaped into a narrow projection in between the rutella (Fig. $6 \mathrm{~b}, \mathrm{c})$. The front of the lateral lips appears to be composed of the same type of smooth integument that forms the pouch in Osperalycus (Fig. 6a). A ventral suture (s) runs along the midline of the subcapitulum in both genera. This is where the smooth integument of the lateral lips adjoin (Fig. 6). The rutella are large and convergent (Fig. 7b-d; 8). The rutella meet, but unlike Osperalycus, there is very little, if any, overlap.

The rutella of Gordialycus sp. A are dorsoventrally expanded, creating a barrier in front of the chelicerae (Fig. 6b). The dorsal and ventral edges of the rutella curve back under and over the space between the lateral lips and the rutellum (Fig. 7b, d). But the ventral edges of the rutella do not extend all the way in to seal the gap between the rutella and the lateral lips (Fig 6b; 7c). The front of the lateral lips adjoins the meeting point of the rutella (Fig. 7c). 
By contrast, the ventral margins of the rutella of Gordialycus sp. B form a contiguous boundary with the lateral lips (Fig. 6c). The opening that is present in the gnathosomal venter of Gordialycus sp. A is sealed by the expansion of the rutella in Gordialycus sp. B.. The rutella of this species also have narrow hair-like extensions protruding from the front (Fig. 6c; 8). These are clearly absent in Gordialycus sp. A.

The labrum of Gordialycus is relatively long and narrow, and always projects diagonally down in between the rutella.

The chelicerae of both species of Gordialycus are almost twice as long as those of Osperalycus $(\sim 22 \mu \mathrm{m})$, each with a single seta located dorsolaterally, proximal to the fixed and movable digit. In common with Osperalycus, the movable digits slant outwards and away from one another (Fig. 7a, b). This allows them to fit on either side of the lateral lips and the overlying labrum when the chelicerae are placed down against them. When a chelicera of Gordialycus sp. $\mathrm{A}$ and $\mathrm{B}$ is pushed up against the rutellum, the movable digit slots into the gap between the rutellum and the lateral lips (Fig. 7d: $\mathrm{Md}$ and $\mathrm{Ru}$ ). In Gordialycus sp. A, the movable digits can be clearly seen to be proximal to the adoral setae (or) (Fig. 6d). But the movable digits cannot be viewed from the venter of the gnathosoma in Gordialycus sp. B because of the contiguous boundary between the lateral lips and the rutella (Fig. 6c); the movable digit slots into a cavity on either side of lateral lips (Fig. 8).

The palps of both species of Gordialycus are very similar in length to those of Osperalycus $(\sim 10 \mu \mathrm{m})$, with the same number and arrangement of setae as for Osperalycus (tarsus $=$ three ventral, two dorsal and one anterior; genu = one dorsal). The anterior seta also has a cup-shaped or concave tip (Fig 5c-d). Similar to Osperalycus, the trichoid setal tips of the palp tarsus reach near to the seta with the cup-shaped tip, a difference being that all five setae do this instead of just four, as in Osperalycus. The palps are distinguishable from Osperalycus in having an additional segment at the base - a trochanter. Whereas Gordialycus also has two cuticular protuberances at the base of the cup-shaped seta, it lacks the posterior cuticular protuberance at the dorsum of the palp tarsus. The cup of the cup-shaped seta of Gordialycus sp. A has a diameter of $1.3 \mu \mathrm{m}$. The length and minimal thickness of the stem of the cup-shaped seta is 1.5 and $0.4 \mu \mathrm{m}$, respectively. The cup of Gordialycus sp. B is slightly oval (length $=2.6 \mu \mathrm{m}$; width = $2.2 \mu \mathrm{m})$. It is also distinctly larger than the cup of both Osperalycus and Gordialycus sp. A. The cup-shaped seta of Gordialycus sp. B has a short and thick stem (length $=1.1 \mu \mathrm{m}$; minimal thickness $=0.7 \mu \mathrm{m})$.

\subsection{Other genera}

The mouthparts of Cunliffea and cf. Psammolycus are clearly distinct from Osperalycus and Gordialycus. In Cunliffea and cf. Psammolycus, the rutella are more attenuated than in Gordialycus and Osperalycus. These rutella do not meet one another and they do not reinforce a pouch. The palps of both Cunliffea and cf. Psammolycus do not have any highly modified setae (Fig. 5e, f).

\section{Discussion}

\subsection{A rupturing mechanism for microbivory}


Particulate feeding mites that possess rutella will typically use their chelicerae to pull their food substrate (e.g. a hyphal strand) between the sharp, and often dentate, anterior edges of the rutella, causing the food substrate to break up for the purposes of ingestion (Théron, 1979). In both Osperalycus and Gordialycus the rutella have converged so that their anterior edges now meet or overlap. Their anterior edges therefore do not project out for the purpose of cutting up food particles. Furthermore, in Osperalycus the rutella are pressed up against the outside of a pouch, whereas in Gordialycus the dorsal edges of the rutella project up or back rather than forward. The rutella are therefore not positioned or angled to present a cutting edge for food items that are being pulled back and into the gnathosoma. But this is to be expected, considering that the Nematalycidae appear to be fluid feeders rather than particulate feeders.

We hypothesize that the unusual mouthpart morphology of Osperalycus and Gordialycus is an adaptation for feeding on the fluid contents of small microorganisms (diameter $<5 \mu \mathrm{m}$ ). A rupturing mechanism is indicated by a barrier in front of the chelicerae (a rutella or a pouch), which appears to be an adaptation for crushing microorganisms that can be placed between this barrier and the chelicerae when they are not fully extended. A rupturing mechanism is also suggested by the way that the chelicerae can be inserted tightly between convergent rutella, or within a reinforced pouch, while also being in the immediate proximity of the mouth. A tight slotting mechanism helps to ensure that the food organism is completely squeezed for the purposes of extracting its fluid contents. Once a microorganism is ruptured, the fluids would be contained by the modified rutella or pouch before they are drawn up underneath a narrow labrum that is inserted between the rutella or within the pouch. The labrum forms the roof of the preoral cavity, whereas the lateral lips form the floor. The preoral cavity, which opens into the rupturing structure (pouch/rutella), is therefore used to draw fluid out of the rupturing structure and into the mouth. .

These mites can probably only feed on what they can pick up and fit into their holding structure - small single celled organisms such as bacteria or yeasts. The chelicerae, which are pointed and chelate, would appear to break up food in the conventional ways - piercing and slicing - while the microorganism is being held in place. However, it may be that the movable digits have to close against the fixed digits in order for the cheliceral digits to completely slot into the containing structure.

\subsection{Modifications of the palp}

This mode of feeding is obviously only possible if the mite can pick up a microorganism without puncturing or crushing it before placing it into the holding structure. Both genera have very similar palps, with modified setae that appear to be adapted for this function. The short length of the palps $(\sim 10 \mu \mathrm{m})$ makes them suitable for this task. A seta on the palp tarsus has a tip that has been modified into a cup-like structure that has the appropriate shape, size and location for picking up small microorganisms and then delicately maneuvering them (Fig. 5a-d; 9). The smooth and concave surface of the cup should provide a much greater surface area of attachment to the microorganism than between the microorganism and the uneven and convex surfaces of the soil particles or other microorganisms contacting it. Attractive intermolecular forces, such as capillarity and van der Waals, should then be sufficient to pick the microorganism up. The cups also appear pliable and can be seen to bend when pressed up against other surfaces. This means that they can probably accommodate some variation in the size or shape of the microorganism

they are attached to. Although the cups look like they are adapted for suction, some specimens 
appear to have cups with uneven rims that would greatly compromise their ability for that function (Fig. 4c).

If the surface of both the microorganism and the cup are smooth enough to enable a sufficiently close contact $(<5 \mathrm{~nm})$, van der Waals forces are likely to be important to the attachment. At greater distances, retardation effects cause the van der Waals force to rapidly decay (Israelachvili, 2011), and the relative strength of other intermolecular forces, including capillarity, become more important. The species of Nematalycidae with the smallest cup is Osperalycus tenerphagus. The cup of this mite has an approximately $5 \times 10^{-13} \mathrm{~m}^{2}$ area of contact (diameter $=0.8 \mu \mathrm{m}$ ) - assuming every part of the cup's interior surface is in contact with the substrate. At a contact distance of $5 \mathrm{~nm}$, the van der Waals adhesion (detachment) force between the cup and a sphere with a diameter of $3.5 \mu \mathrm{m}$ - the typical size and shape of a yeast cell that would fit into the feeding pouch - is 18.3 times as great as the adhesion force between the sphere and a flat surface (Leckband and Israelachvili, 2001). When the weak force of gravity is also accounted for (weight based on the mass of water contained within the yeast cell), the difference decreases to a factor of 6.3 (Hamaker constant $=1 \times 10^{-20}$ ). The larger cups of Gordialycus may be used to pick up larger microorganisms (but see the explanation for Gordialycus sp. B below).

Note that capillarity might be important to the attachment if greater contact distances cause retardation effects with respect to the van der Waals forces. Under wet or very moist conditions, large meniscus bridges between a microorganism and another surface would require the seta to have a cup with a larger contact area in order for the setal cup to pick up the microorganism. This feeding mechanism might therefore be more effective under relatively dry conditions.

The location of the cup at the tip of a flexible seta helps to avoid puncturing or crushing the microorganism (preventing any potential waste of the fluid contents). The form and flexibility may also assist in the attachment - the stem of the seta should have sufficient flexibility to cause the cup to align squarely with the surface of the microorganism as it is being pressed against it, therefore enabling the necessary angle for a good attachment. The palp tarsal setae that curve into the proximity of the cup could be chemosensory, being well positioned to detect any material that is either attached to the cup or very close to it. (Fig. 5b-d). But this would require the setae to have terminal pores, which is not yet known. These setae may also, or instead, function as basic mechanoreceptors for sensing if the cup has successfully attached to or detached from a microorganism. The two short cuticular protuberances present at the base of the seta with the cup (Fig. 5a, c, d), may be used as scrapers for dislodging microorganisms that are strongly attached to any surface via extracellular polymeric adhesives. Such substances are known to be secreted by many different types of microorganisms (Sutherland, 1982; McCourtie and Douglas, 1985; Hokputsa et al., 2003; Long et al., 2009). These protuberances may also or instead function to prevent the seta with the cup from flexing back too far when it is being used to pick up food items, therefore preventing the damage of a crucial feeding structure. The dorsal tarsal protuberance, which is exclusive to Osperalycus tenerphagus, has a more posterior position and may therefore have a different function.

\subsection{Osperalycus tenerphagus}

The pouch of Osperalycus tenerphagus appears to be soft based on its complete lack of visibility under a light microscope (Fig. 4b). The rutella give support and shape to the pouch, restricting its movement during the puncturing of the food contents. The hard bases of the rutella, which intrude into the sides of the pouch, cause the pouch to narrow distally (Fig. 4). The 
convergent and narrow digits of the rutella reinforce and shape the front of the pouch as it increasingly narrows towards the terminus. A microorganism would therefore be channeled into a firmly held position by simply pushing it into the reinforced pouch with the chelicerae. Once the microorganism is tightly in place, further extension of the chelicerae would crush or puncture the microorganism, causing the liquid contents to spill out into the pouch (Fig. 9). The extension of the chelicerae would also channel any solid or liquid inside the pouch into the corner of the pouch, which is buttressed by the flanged and overlapping tips of the rutella (Fig. 4c). The rutella therefore also appear to be shaped and situated for the reinforcement of the most vulnerable part of the pouch.

\subsection{Gordialycus sp. A}

The gap between the rutella and the lateral lips (Fig. 7c) provides a slot for the movable digit of each chelicera (Fig. 7d). This would enable Gordialycus sp. A to effectively rupture any small microorganism that is placed in between the rutellum and the lateral lips. As the chelicerae extend forwards into the microorganism, the fixed digit would pin it in place against the rutellum. The movable digit would then be able to slice into it from the side. The ventral opening (the gap between the ventral edge of the rutellum and the lateral lips) may provide space for the movable digit to articulate during or after the extension of the chelicera.

As both piercing and slicing occurs, the microorganism is tightly held between the lateral lips and the rutellum. The rutellum is appropriately shaped to hold a microorganism firmly in place due to the way that the front of the rutellum curves back over and under the slot for the movable digit (Fig. 7b, d).

\subsection{Gordialycus sp. B}

The gap in the venter that is present in Gordialycus sp. A is sealed by the expansion of the rutella in Gordialycus sp. B, which would prevent the loss of fluid via the venter. Therefore, although the rutella of Gordialycus sp. B would be able to hold microorganisms in place, they may also function as an effective container of the fluid that is ejected from ruptured microorganisms (Fig. 8). The movable digits would slot in between the rutella on either side of the lateral lips. Anything in between the rutella would therefore probably be ruptured in a similar way to the mechanism described for Gordialycus sp. A. However, it may be that the absence of a ventral opening between the rutellum and the lateral lips reduces the maneuverability of the movable digits during the rupturing process.

Although the subcapitulum of Gordialycus sp. B functions as a suitable fluid container, it would be susceptible to the loss of microorganisms over the edge as the chelicerae push into them. This is because the front of the rutellum does not curve back dorsally, in contrast to Gordialycus sp. A. The rutella therefore appear to have reduced functionality with respect to holding the microorganism in place. This function may be instead partially served by the cupshaped palp seta (Fig. 5d; 8). In this species the cup is much larger (roughly double the diameter of the setal cup of Gordialycus sp. A and triple that of Osperalycus tenerphagus). The stem of the seta is also much thicker and shorter than that of Osperalycus tenerphagus or Gordialycus sp. A. These would be useful modifications if, in addition to picking up microorganisms, this seta functioned to hold the microorganisms down while they are in between the rutella during the rupturing process (Fig. 8). The reduced length and increased width of the stem would be 
important in giving the seta additional rigidity when it is pushed down against the microorganism (a long, thin and highly flexible stem would be useless in this regard). The increased contact area of the cup would provide a larger and stronger attachment. There is no other obvious reason for the modified seta to have a much larger cup while also having a much shorter and thicker stem. Furthermore, the modified seta appears to be the only structure that could prevent the microorganism from slipping over the edge of the rutella during the extension of the chelicerae.

The hair-like extensions at the front of the rutella may function to help reduce spillage or loss of fluid (Fig. 6c; 8). The extensions would cause fluid to accumulate at the dorsal edge of the rutella instead of spilling over. They may therefore have a similar function to the tritosternum of the Mesostigmata, which has hair-like extensions for helping to trap fluid against the venter of the gnathosoma (Wernz and Krantz, 1976).

\subsection{Ecological relevance of the rupturing mechanism}

Like other nematalycids, Osperalycus and Gordialycus appear to live exclusively in mineral soils or sands. Their unusual integumental morphology is clearly well adapted for moving around in these habitats (Bolton et al., 2015). Gordialycus is frequently found in deserts, beaches and sand dunes (see appendix; Coineau et al., 1967; Silva et al., 1989; Norton et al., 2008). Osperalycus has been collected from a deep mineral soil from a prairie and a young chestnut plantation (Bolton et al., 2014). The soft integument and vermiform bodies of the Nematalycidae would make them vulnerable to the many predatory mites and other arthropods that live at relatively high densities in organically rich soils and plant litters. Organically impoverished soils therefore likely provide a refuge from predation and perhaps also competition.

If our functional-morphology argument is correct, by allowing Osperalycus and Gordialycus to feed on individual microorganisms, their cell-rupturing mouthparts appear to provide a novel solution for the main challenge presented by the adverse and organically impoverished habitats in which they live. Microorganisms are ubiquitous. They can provide a reliable source of nutrients in adverse and organically impoverished habitats such as deserts and subsurface environments, where they make up an important component of their ecosystems (Skujinš 1984; Dobbins et al., 1992; Vishniac, 2006; Pointing \& Belnap 2012). It should therefore be expected that many of the microarthropods that live in these habitats are specialized for feeding on microorganisms, especially as many other types of potential food organisms are either absent from these habitats or less evenly distributed within them.

Furthermore, because food of any kind is relatively scarce in organically impoverished environments, there should be strong selection for efficient feeding. Cutting or grinding up small microorganisms with chelate mandibles or chelicerae should normally be wasteful, with a large proportion of the relatively small volume of fluid adhering to surfaces from which it cannot be readily channeled into the mouth. By rupturing the microorganism in a structure that is proximal to the mouth, a large amount of waste is avoided.

The evolution of these rupturing mechanisms raises the question of why these mites did not instead switch to particulate feeding, where microorganisms would be swallowed whole and digested in the gut. Particulate feeding is unusual within the Arachnida, and has only evolved in a small number of lineages. Part of the reason for this may be that this mode of feeding is relatively costly due to the enzymes needed to either penetrate or digest the cell walls of microorganisms (Hubert et al., 2001; Hubert et al., 2004). These costs are normally met through 
the direct metabolism of the enzymes, or indirectly by hosting microbial symbionts (Smrž and Čatská, 2010). In an organically impoverished environment it may be more efficient to circumvent these costs by mechanically separating the fluid contents from the cell wall prior to ingestion.

\section{Conclusion}

Although it is not yet certain how the mouthparts of Gordialycus and Osperalycus function, a rupturing mechanism is consistent with many different features of these mites. A hard or reinforced structure is present directly in front of the chelicerae, providing an obvious way to secure a microorganism during its rupture. Furthermore, in both genera the preoral cavity extends directly into the space between the rutella, where the fluid would be released from the ruptured microorganism.

A collecting mechanism also appears to be present. There is a remarkable degree of resemblance between the palps - the hypothesized collecting structures - of the two genera. In the other genera that were observed with LT-SEM (Cunliffea and Psammolycus), neither a holding structure nor a collecting mechanism is apparent. This is fully consistent with the rupturing mechanism hypothesis, which requires a means of maneuvering microorganisms into a holding structure during the puncturing process.

A couple of issues remain unsolved. It is not known how the cell wall of the microorganism is removed from the feeding apparatus after it has been ruptured. It is also not yet clear exactly how the simple setae and cuticular protuberances on the palps function.

As these mouthparts are most plausibly interpreted as being adapted for feeding on very small food items, they may represent one of the most unusual and extreme adaptations to microbivory throughout the Arachnida - a possible result of strong selective pressure for more efficient ways of feeding on small microorganisms in organically impoverished environments.

\section{Appendices}

\subsection{Appendix A - Material examined under LT-SEM}

Osperalycus tenerphagus - U.S.A., Ohio, Franklin Co., Kinnear Road, 39.9990 N -83.0468 W, silty clay loam from suburban prairie (including shrubs, grasses and small trees); collector: Samuel Bolton, August-2011, $50 \mathrm{~cm}$ deep: deutonymph/tritonymph $\times 1$, tritonymph $\times 2$, adult $\times 7$.

Gordialycus sp. A - U.S.A., California, Imperial County, Algodones Dunes, Imperial Sand Dunes Recreation Area, 32.9811 N -115.1317 W, bottom of sand dune; collector: Samuel Bolton, October-2013, $10 \mathrm{~cm}$ deep: larva $\times 3$; nymph/adult $\times 5$.

Gordialycus sp. B - U.S.A., Indiana, Lake County, Marquette Park, 41.6156 N -87.2743 W, top of sand dune; collector: Samuel Bolton, May-2013, $10 \mathrm{~cm}$ deep: nymph/adult $\times 6$.

Cunliffea strenzkei - U.S.A., Florida, Highlands Co., Highlands Hammock Park, 27.4713 N $81.5646 \mathrm{~W}$, sandy soil from sparsely wooded area; collector: Samuel Bolton, April-2011, $30 \mathrm{~cm}$ deep: tritonymph/adult $\times 2$. 
cf. Psammolycus sp. n. - U.S.A., Florida, Highlands Co., Highlands Hammock Park, 27.4713 N $81.5646 \mathrm{~W}$, sandy soil from sparsely wooded area; collector: Samuel Bolton, April-2011, $30 \mathrm{~cm}$ deep: post-larva $\times 2$.

Note that all adults were female.

\subsection{Appendix B-Percent increase in mouthparts from larva to adult.}

Table 1. Distance from the base of the chelicera (excluding trochanter) to the dorsal seta of the fixed digit $(\mu \mathrm{m})$.

\begin{tabular}{|c|c|c|c|c|c|c|c|}
\hline \multirow[t]{2}{*}{ Species } & \multicolumn{3}{|c|}{ Larva } & \multicolumn{3}{|c|}{ Adult } & \multirow{2}{*}{$\begin{array}{l}\text { Percent } \\
\text { increase }\end{array}$} \\
\hline & $\mathrm{n}$ & $x$ & $\sigma$ & $\mathrm{n}$ & $x$ & $\sigma$ & \\
\hline Osperalycus tenerphagus & 5 & 8.6 & 0.2 & 7 & 8.7 & 0.2 & 1 \\
\hline Gordialycus sp. C & 4 & 20.6 & 1.1 & 4 & 24 & 1.5 & 19 \\
\hline
\end{tabular}

Table 2. Distance between the dorsocentral seta on the palp-tarsus and the dorsocentral seta on the palp-genu $(\mu \mathrm{m})$.

\begin{tabular}{|c|c|c|c|c|c|c|c|}
\hline \multirow[t]{2}{*}{ Species } & \multicolumn{3}{|c|}{ Larva } & \multicolumn{3}{|c|}{ Adult } & \multirow{2}{*}{$\begin{array}{l}\text { Percent } \\
\text { increase }\end{array}$} \\
\hline & $\mathrm{n}$ & $x$ & $\sigma$ & $\mathrm{n}$ & $x$ & $\sigma$ & \\
\hline Osperalycus tenerphagus & 5 & 3.5 & 0.3 & 7 & 3.7 & 0.2 & 7 \\
\hline Gordialycus sp. C & 4 & 4.0 & 0.1 & 4 & 4.6 & 0.2 & 14 \\
\hline
\end{tabular}

Measurements were obtained from slide mounted specimens using a Zeiss Axioskop ${ }^{\mathrm{TM}}$ equipped with a phase contrast optical system. Osperalycus tenerphagus was collected by Samuel Bolton (2010 to 2011) from Ohio (USA), Franklin Co., Kinnear Road, 39.9990 N -83.0468 W. Gordialycus sp. C (two lateral claws on legs I and II and single lateral claws on legs III and IV) was collected by John Kethley (1985) from an unknown location. The Gordialycus sp. C specimens were borrowed from the Field Museum, Chicago, USA.

\section{Acknowledgements}

This research was partly funded by the Smithsonian Institution (pre-doctoral fellowship to the first author). Thanks to Chris Pooley for editing and arranging the LT-SEM image plates. Thanks also to Elizabeth Murray and John Heraty for the use of their lab facilities at the University of Riverside. An acknowledgment is also due to the U.S. National Park Service for granting the first author permission to collect from the Indiana Dunes National Lakeshore. Mention of trade names or commercial products in this publication does not imply recommendation or endorsement by the USDA or The Ohio State University. Figures 1 and 3 to 8 in this publication are sourced from: US Department of Agriculture, Agricultural Research Service, Electron and Confocal Microscopy Unit, Beltsville, Maryland, USA. These images are in the public domain. 


\section{References}

Acosta, L.E. and Machado, G., 2007. Diet and foraging, In: Pinto-da-Rocha, R., Machado, G. and Giribet, G. (Eds.), Harvestmen: The biology of Opiliones. Harvard University Press, Cambridge, MA, pp. 309-338.

Akimov, I.A., 1979. Morphological and functional characteristics of the mouthparts of Acaridae mites (Acaridae Ewing \& Nesbitt, 1942), In: Piffl, E. (Ed.), Proceedings of the 4th International Congress of Acarology, Saalfelden, Austria. Akadémiai Kiadó, Budapest, Hungary, pp. 569-574.

Alberti, G., 2008. On corniculi, rutella and pseudorutella - some ultrastructural details of keycharacters in Acari (Arachnida). Annales Zoologici 58, 239-250.

Alberti, G. and Coons, L.B., 1999. Volume 8C. Acari: Mites, In: Harrison, F.W. and Foelix, R.F. (Eds.), Microscopic anatomy of invertebrates. Vol. 8. Chelicerate Arthropoda. John Wiley \& Sons, Inc., New York, NY, pp. 515-1215.

Beard, J.J., Ochoa, R., Bauchan, G.R., Welbourn, W.C., Pooley, C. and Dowling, A.P.G., 2012. External mouthpart morphology in the Tenuipalpidae (Tetranychoidea): Raoiella a case study. Experimental and Applied Acarology 57, 227-255.

Bolton, S.J., Klompen, H., Bauchan, G.R. and Ochoa, R., 2014. A new genus and species of Nematalycidae (Acari: Endeostigmata). Journal of Natural History, 48, 1359-1373.

Bolton, S.J., Bauchan, G.R., Ochoa, R., Pooley, C. and Klompen, H., 2015. The role of the integument with respect to different modes of locomotion in the Nematalycidae (Endeostigmata). Experimental and Applied Acarology, 65, 149-161.

Cohen, A.C., 1995. Extra-oral digestion in predaceous terrestrial arthropoda. Annual Review Of Entomology 40, 85-103.

Cohen, A.C., 1998. Solid-to-liquid feeding: The inside(s) story of extra-oral digestion in predaceous arthropoda. American Entomologist 44, 103-117.

Coineau, Y., Fize, A. and Delamere Deboutteville, C., 1967. Découverte en France des acariens Nematalycidae Strenzke à l'occasion des traveaux d'aménagement du LanguedocRousillon. Comptes rendus de l'Academie des Sciences, Paris 265, 685-688.

Cunliffe, F., 1956. A new species of Nematalycus Strenzke with notes on the family (Acarina, Nematalycidae). Proceedings of the Entomological Society of Washington 58, 353-355.

Di Palma, A., Nuzzaci, G. and Alberti, G., 2009. Morphological, ultrastructural and functional adaptations of the mouthparts in cheyletid mites (Acari: Actinedida: Cheyletidae). International Journal of Acarology 35, 521-532.

Dinsdale, D., 1974. Feeding activity of a phthiracarid mite (Arachnida: Acari). Journal of the zoological society of London 174, 15-21.

Dobbins, D.C., Aelion, C.M. and Pfaender, F., 1992. Subsurface, terrestrial microbial ecology and biodegradation of organic chemicals: A review. Critical Reviews in Environmental Control, 22, 67-136.

Evans, G.O., 1992. Principles of Acarology. C.A.B. International, Wallingford.

Grandjean, F., 1957. L'infracapitulum et la manducation chez les Oribates et d'autre Acariens. Annales Des Sciences Naturelles comprenant la zoologie 19, 233-281.

Haupt, J. and Coineau, Y., 1999. Ultrastructure and functional morphology of a nematalycid mite (Acari: Actinotrichida: Endeostigmata: Nematalycidae): adaptations to mesopsammal life. Acta Zoologica 80, 97-111. 
Heethoff, M. and Norton, R.A., 2009. Role of Musculature During Defecation in a ParticleFeeding Arachnid, Archegozetes longisetosus (Acari, Oribatida). Journal of Morphology 270, 1-13.

Hillyard, P.D. and Sankey, J.H.P., 1989. Harvestmen: keys and notes for the identification of the species, 2nd ed. E.J. Brill, Leiden-New York-Copenhagen-Cologne.

Hokputsa, S., Hu, C., Paulsen, B.S. and Harding, S.E., 2003. A physico-chemical comparative study on extracellular carbohydrate polymers from five desert algae. Carbohydrate Polymers 54, 27-32.

Hubert, J., Jarosǐk, Z., Mourek, J., Kubátová, A. and Zdárková, E., 2004. Astigmatid mite growth and fungi preference (Acari: Acaridida): Comparisons in laboratory experiments. Pedobiologia 48, 205-214.

Hubert, Z., Žilová, M. and Pekár, S., 2001. Feeding preferences and gut contents of three panphytophagous oribatid mites (Acari: Oribatida). European Journal of Soil Biology 37 , 197-208.

Israelachvili, J.N., 2011. Intermolecular and surface forces: revised third edition., 3rd ed. Academic Press, Waltham, MA.

Kaliszewski, M., Athias-Binche, F. and Lindquist, E.E., 1995. Parasitism and parasitoidism in Tarsonemina (Acari: Heterostigmata) and evolutionary considerations. Advances in Parasitology 35, 335-367.

Kethley, J., 1990. Acarina: Prostigmata (Actinedida), In: Dindal, D.L., (Ed.), Soil Biology Guide. John Wiley \& Sons, Inc., New York, NY, pp. 667-756.

Kethley, J.B., 1991. A procedure for extraction of microarthropods from bulk samples with emphasis on inactive stages. Agriculture, Ecosystems and Environment 34, 193-200.

Krantz, G.W. and Lindquist, E.E., 1979. Evolution of phytophagous mites (Acari). Annual Review Of Entomology 24, 121-158.

Krenn, H.W. and Aspöck, H., 2012. Form, function and evolution of the mouthparts of bloodfeeding Arthropoda. Arthropod Structure \& Development 41, 101-118.

Leckband, D. and Israelachvili, J.N., 2001. Intermolecular forces in biology. Quarterly Review of Biophysics 34, 105-267.

Long, G., Zhu, P., Shen, Y. and Tong, M., 2009. Influence of extracellular polymeric substances (EPS) on deposition kinetics of bacteria. Environmental Science \& Technology 43, 23082314.

Muma, M.H., 1966. Feeding behavior of North American Solpugida (Arachnida). The Florida Entomologist 49, 199-216.

McCourtie, J. and Douglas, L.J., 1985. Extracellular polymer of Candida albicans: isolation, analysis and role in adhesion. Journal of General Microbiology 131, 495-503.

Norton R.A, Oliveira A.R, De Moraes G.J., 2008. First Brazilian records of the acariform mite genera Adelphacarus and Gordialycus (Acari : Adelphacaridae and Nematalycidae). International Journal of Acarology 34, 91-94.

Pointing, S.B. and Belnap, J., 2012. Microbial colonization and controls in dryland systems. Nature Reviews Microbiology 10, 551-652.

Schubart, H.O.R., 1973. The occurence of Nematalycidae (Acari, Prostigmata) in Central Amazonia with a description of a new genus and species. Acta Amazonica 3, 53-57.

Silva, S., Whitford, W.G., Jarrell, W.M. and Virginia, R.A., 1989. The microarthropod fauna associated with a deep rooted legume, Prosopis glandulosa, in the Chihuahuan desert. Biology and fertility of soils 7, 330-335. 
Skujinš, J., 1984. Microbial ecology of desert soils. Advances in microbial ecology, 7, 49-91.

Smrž, J. and Čatská, V., 2010. Mycophagous mites and their internal associated bacteria cooperate to digest chitin in soil. Symbiosis 52, 33-40.

Strenzke, K., 1954. Nematalycus nematoides $\mathrm{n}$. gen n. sp. (Acarina Trombidiformes) aus dem Grundwasser der Algerischen Küste. Vie et Milieu 4, 638-647.

Sutherland, I.W., 1982. Microbial exopolysaccharides - their role in microbial adhesion in aqueous systems. Critical Reviews in Microbiology 10, 173-201.

Théron, P.D., 1979. The functional morphology of the gnathosoma of some liquid liquid and solid feeders in the Trombidiformes, Cryptostigmata and Astigmata (Acarina), In: Piffl, E. (Ed.), Proceedings of the 4th International Congress of Acarology, Saalfelden, Austria. Akadémiai Kiadó, Budapest, Hungary, pp. 575-579.

Vishniac, H.S., 2006. A multivariate analysis of soil yeasts isolated from a latitudinal gradient. Microbial Ecology 52, 90-103.

Walter, D.E., 1988. Predation and mycophagy by endeostigmatid mites (Acariformes: Prostigmata). Experimental and Applied Acarology 4, 159-166.

Walter DE. 2009. Suborder Endeostigmata, In: Krantz GW, Walter DE, (Eds.), A manual of acarology. Texas Tech University Press, Lubbock, TX, pp. 421-429.

Walter, D.E. and Lindquist, E.E., 1989. Life history and behavior of mites in the genus Lasioseius (Acari: Mesostigmata: Ascidae) from grassland soils in Colorado USA with taxonomic notes and description of a new species. Canadian Journal of Zoology 67, 2797-2813.

Walter, D.E. and Proctor, H.C., 1998. Feeding behaviour and phylogeny: Observations on early derivative Acari. Experimental and Applied Acarology 22, 39-50.

Wernz, J.G. and Krantz, G.W., 1976. Studies on the function of the tritosternum in selected Gamasida (Acari). Canadian Journal of Zoology 54, 202-213.

Fig. 1. Vermiform bodies of the Nematalycidae under LT-SEM. (a) Gordialycus sp. A (nymph/adult). (b) Osperalycus tenerphagus (adult female).

Fig. 2. Mouthparts of the Nematalycidae (drawings are differently scaled). (a) General schematic for the mouthparts of the Nematalycidae, representing a transverse section of the gnathosoma between the mouth and the tip of the labrum. (b) Chelicera of Osperalycus tenerphagus. (c) Chelicera of Gordialycus sp. A. La = labrum; Pc $=$ preoral cavity; $\mathbf{L L}=$ lateral lip; $\mathrm{Pa}=$ palp; $\mathrm{Ru}=$ rutellum; $\mathrm{Fd}=$ fixed digit; $\mathrm{Md}=$ movable digit; $\mathrm{Cs}=$ cheliceral shaft; $\operatorname{Tr}=$ trochanter; $\mathrm{Sc}=$ cheliceral seta.

Fig. 3. Dorsal views of the mouthparts of Osperalycus tenerphagus under LT-SEM (different specimens). (a) Digits inserted into the pouch. (b) Digits withdrawn from the pouch- right chelicera twisted out of its natural orientation due to damage. $P o=$ pouch; $R u$ $=$ rutellum; $\mathbf{C s}=$ cheliceral shaft $\mathbf{P t}=$ Palp tarsus; $\mathbf{P g}=$ palp genu; $\mathbf{P f}=$ palp femur; $\mathbf{F d}=$ fixed digit; $\mathrm{Md}=$ movable digit; $\mathrm{Sc}=$ cheliceral seta; $\mathrm{Le}=$ leaf (flap-like extension of the lateral lips).

Fig. 4. The pouch of Osperalycus tenerphagus (different specimens). (a) Dorsal view (chelicerae inserted) under LT-SEM - rutellum highlighted by white outline. (b) Dorsal 
view (chelicerae withdrawn and out of view) under a light microscope (phase contrast) rutellum highlighted with the white outline from (a), revealing the structure to be much more sclerotized than the rest of the gnathosoma. The outline of the labrum (left side only) is demarcated by a dashed line. (c) Anteroventral view under LT-SEM. Cs = cheliceral shaft; Fd = fixed digit; $P o=$ pouch; $R \mathbf{R}=$ rutellum base; $R d=$ rutellum digit; $\mathrm{Su}=$ suture adjoining the lateral lips; $\mathbf{L a}=$ labrum; $\mathbf{L L}=$ lateral lips; $P t=$ palp tarsus; $\mathbf{C u}=$ cup shaped seta-tip (uneven rim); $S=$ seta of the palp tarsus (trichoid); $S c=$ cheliceral seta (trichoid); $\mathbf{C p}=$ cuticular protuberance .

Fig. 5. Palps under LT-SEM (different specimens). (a) Osperalycus tenerphagus - close-up lateral view of the palp seta with cup-shaped tip. (b) Osperalycus tenerphagus - lateral view of the palp tarsus (only structures on the nearest side of the gnathosoma are labelled). (c) Gordialycus sp. A - ventral view of the palp tarsus. (d) Gordialycus sp. B - lateral view of the palp tarsus. (e) Cunliffea strenzkei - lateral view of the palp tarsus. (f) cf. Psammolycus sp. $n$. - lateral view of the palp tarsus. $P t=$ palp tarsus; $P g=$ palp genu; $P f=$ palp femur; $\mathrm{Cu}=$ cup shaped seta-tip; $\mathrm{Cp}=$ cuticular protuberance; $\mathrm{S}=$ seta of the palp tarsus (trichoid); Spg = seta of the palp genu (trichoid); Sc = cheliceral seta (trichoid).

Fig. 6. Ventral views of the lateral lips and rutella under LT-SEM. (a) Osperalycus tenerphagus. (b) Gordialycus sp. A. (c) Gordialycus sp. B. Ru = rutellum; Su = suture adjoining the lateral lips; or $=$ adoral seta; $\mathbf{a}+\mathbf{m}=$ subcapitular seta.

Fig. 7. The mouthparts of Gordialycus sp. A under LT-SEM (different specimens). (a) Dorsolateral view of the chelicerae. (b) Anterior view of the mouthparts - chelicerae partially retracted. (c) Ventral view of the lateral lips and rutella, showing connection between lateral lips and rutella (large arrowhead). Chelicerae withdrawn so that there is a gap between the lateral lips and the rutella. (d) Anterior view of the mouthparts chelicerae extended forwards so that the movable digit (MD) fills in the gap between the lateral lips and the rutella. $\mathrm{Ru}=$ rutellum; $\mathrm{Cs}=$ cheliceral shaft; $\mathrm{Md}=$ movable digit; $\mathrm{Fd}=$ fixed digit; $\mathrm{LL}=$ lateral lips; $\mathrm{Sc}=$ cheliceral seta; or $=$ adoral seta; $\mathbf{P t}=$ palp tarsus; $\mathbf{P g}=$ palp genu.

Fig. 8. Anterior view of the mouthparts of Gordialycus sp. B under LT-SEM - showing that the large cup-shaped seta could be maneuvered to hold a microorganism into the bowl shaped rutella. There is obvious visible damage (probably due to desiccation prior to mounting) - the rutella have pulled away from one another and the lateral lips. They terminate in a hairlike extension. $\mathrm{Cs}=$ cheliceral shaft; $\mathrm{Md}=$ movable digit; $\mathbf{F d}=$ fixed digit; $\mathbf{R u}=$ rutellum; $\mathbf{L L}=$ lateral lips; $P t=$ palp tarsus; $P g=$ palp genu; $P f=$ palp femur; Ptr = palp trochanter; $\mathrm{Cu}=$ cup shaped seta-tip; $\mathrm{S}=$ seta of the palp tarsus (trichoid); Spg $=$ seta of the palp genu (trichoid); $\mathbf{S c}=$ cheliceral seta; $\mathbf{C p}=$ cuticular protuberance

Fig. 9. Dorsal views of the mouthparts of Osperalycus for the three hypothesized stages of feeding on a microorganism (pouch shown as transparent). (a) The cup on the palp tarsus attaches to a microorganism. (b) The palp bends back and over the pouch opening; the chelicerae retract to make space for the microorganism. (c) The chelicerae extend forwards, pushing the microorganism into and against the anteriorly narrowing pouch 
until it ruptures. The fluid contents can then be channeled into the mouth (inside the pouch). Rutella = dark grey; pouch wall = medium grey. 
Table 1. Distance from the base of the chelicera (excluding trochanter) to the dorsal seta of the fixed digit $(\mu \mathrm{m})$.

\begin{tabular}{|l|c|c|c|c|c|c|c|}
\hline \multirow{2}{*}{ Species } & \multicolumn{3}{|c|}{ Larva } & \multicolumn{3}{c|}{ Adult } & Percent \\
\cline { 2 - 8 } & $\mathrm{n}$ & $\bar{x}$ & $\sigma$ & $\mathrm{n}$ & $\bar{x}$ & $\sigma$ & increase \\
\hline Osperalycus tenerphagus & 5 & 8.6 & 0.2 & 7 & 8.7 & 0.2 & 1 \\
\hline Gordialycus sp. C & 4 & 20.6 & 1.1 & 4 & 24 & 1.5 & 19 \\
\hline
\end{tabular}


Table 2. Distance between the dorsocentral seta on the palp-tarsus and the dorsocentral seta on the palp-genu $(\mu \mathrm{m})$.

\begin{tabular}{|l|c|c|c|c|c|c|c|}
\hline \multirow{2}{*}{ Species } & \multicolumn{3}{|c|}{ Larva } & \multicolumn{3}{c|}{ Adult } & Percent \\
\cline { 2 - 8 } & $\mathrm{n}$ & $\bar{x}$ & $\sigma$ & $\mathrm{n}$ & $\bar{x}$ & $\sigma$ & increase \\
\hline Osperalycus tenerphagus & 5 & 3.5 & 0.3 & 7 & 3.7 & 0.2 & 7 \\
\hline Gordialycus sp. C & 4 & 4.0 & 0.1 & 4 & 4.6 & 0.2 & 14 \\
\hline
\end{tabular}


a

b

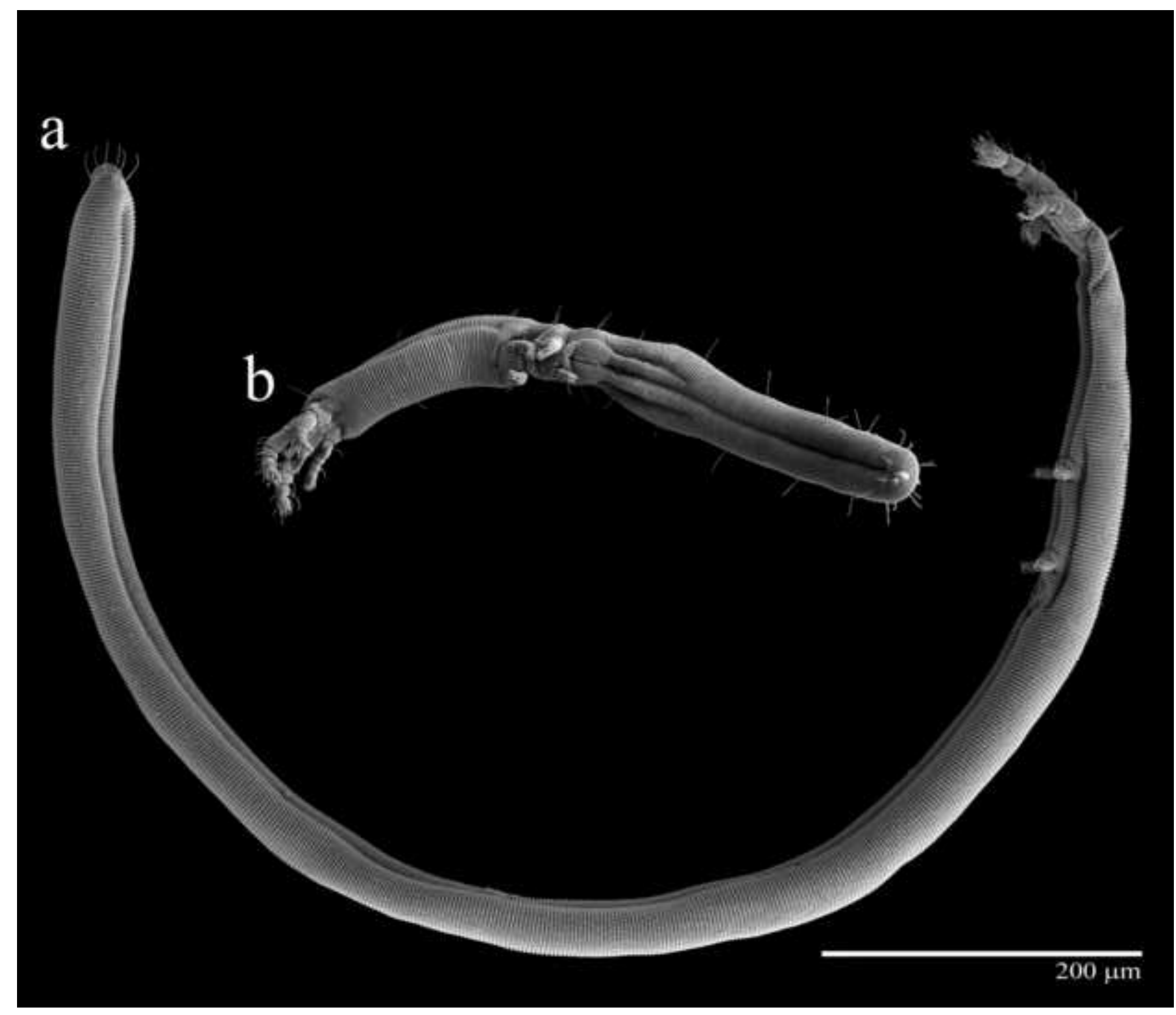




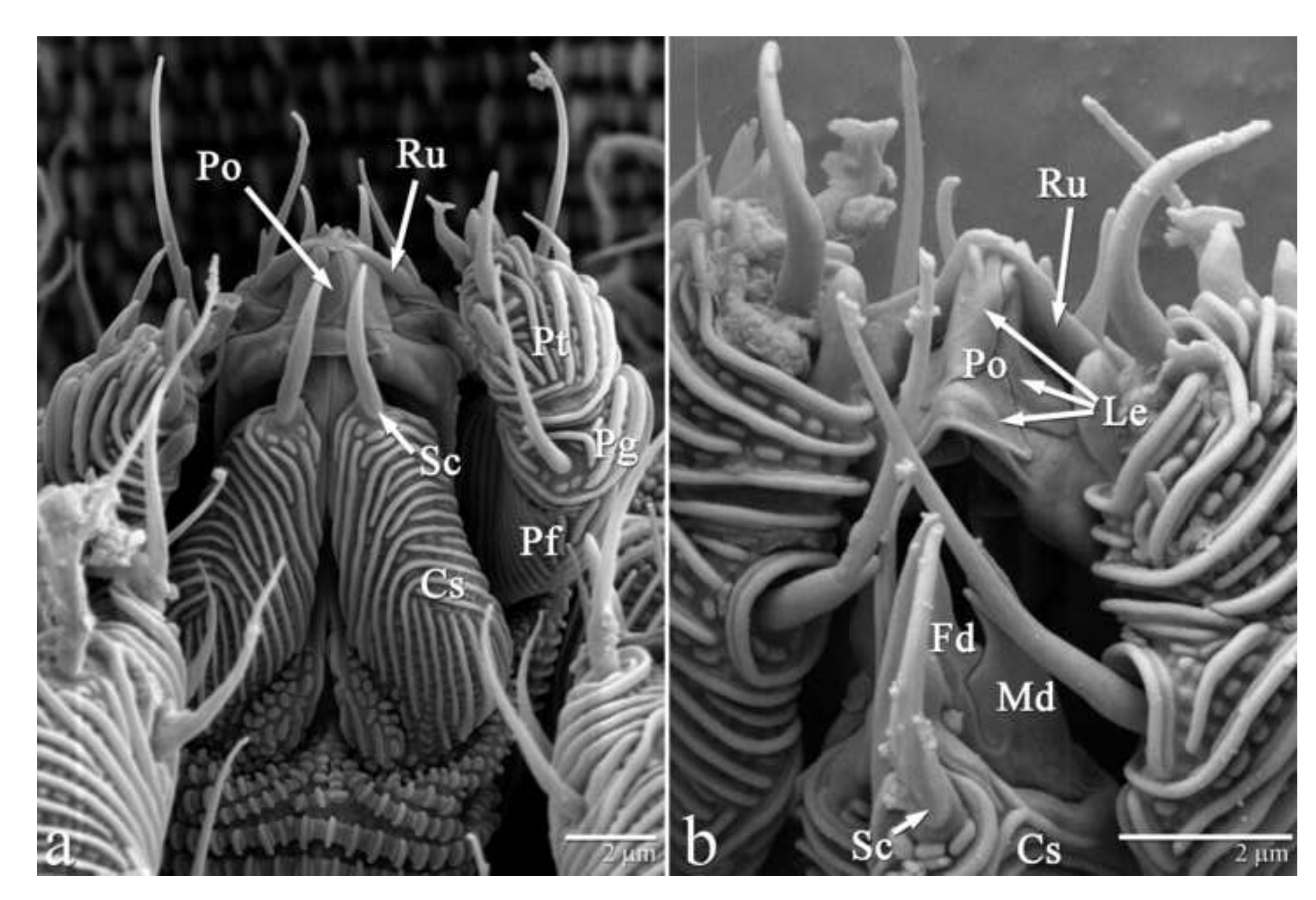

.
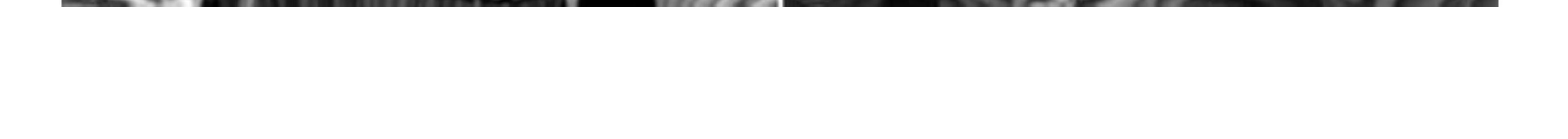
Figure 4
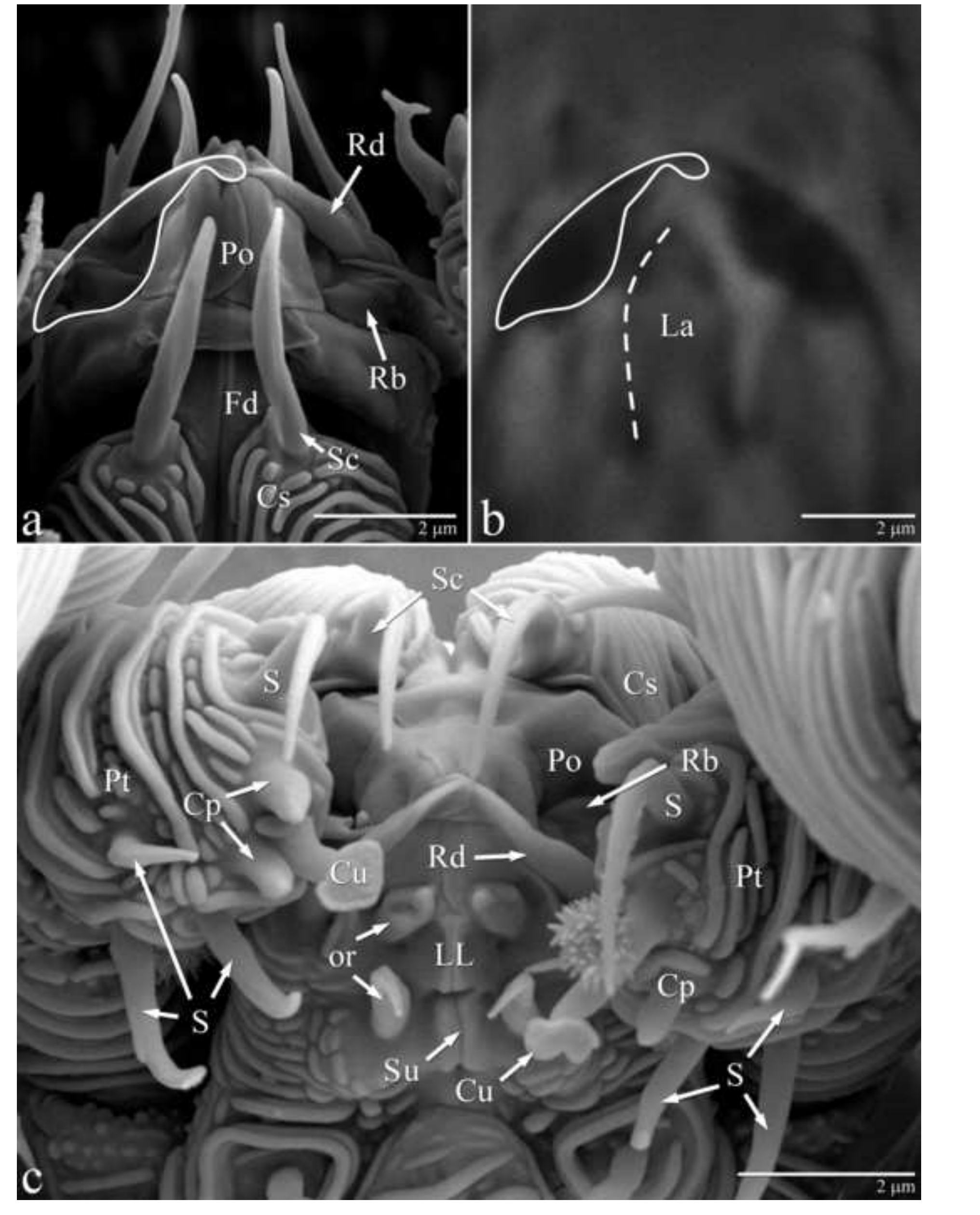

At

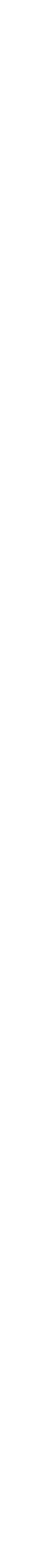

\section{(} . 

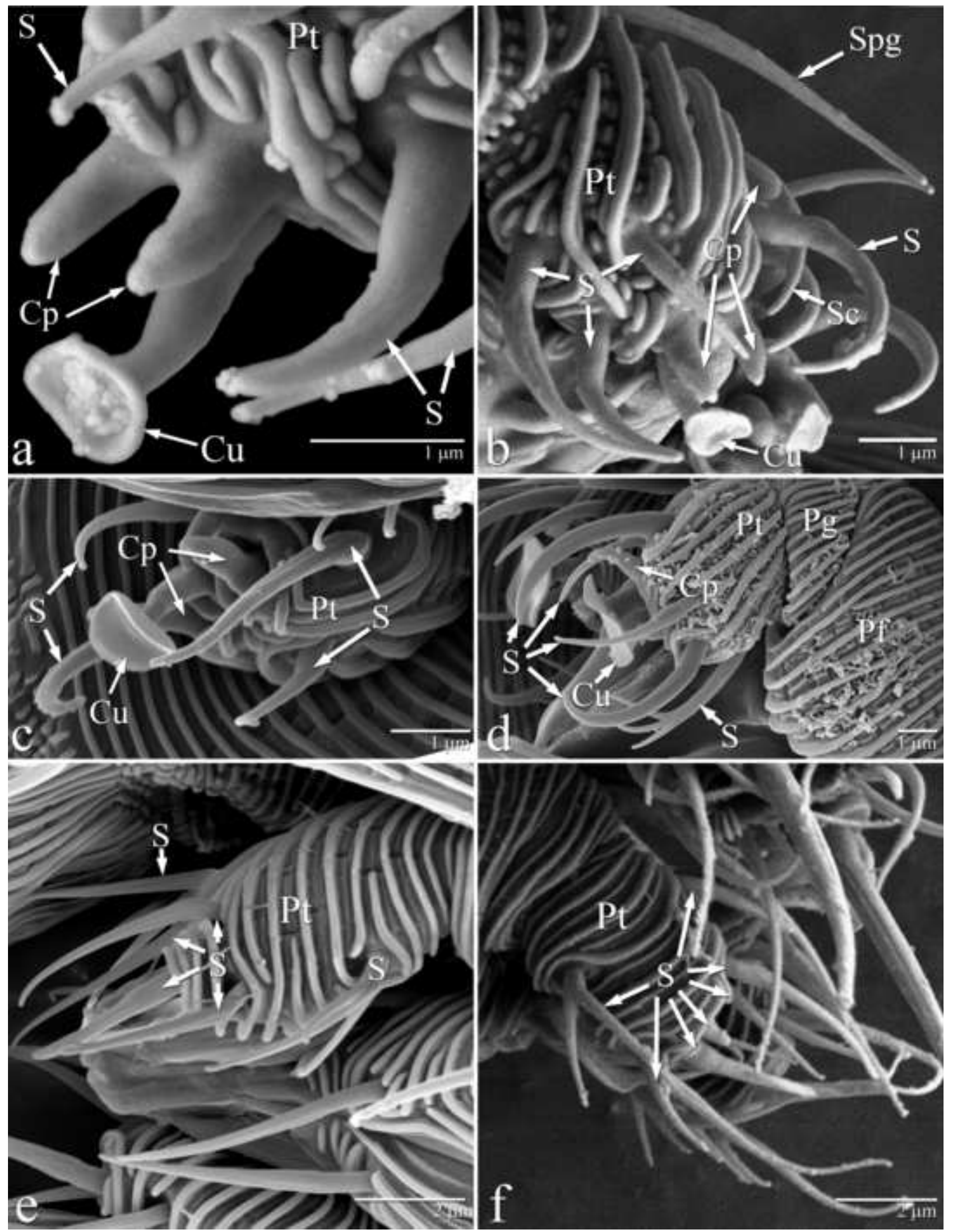
a

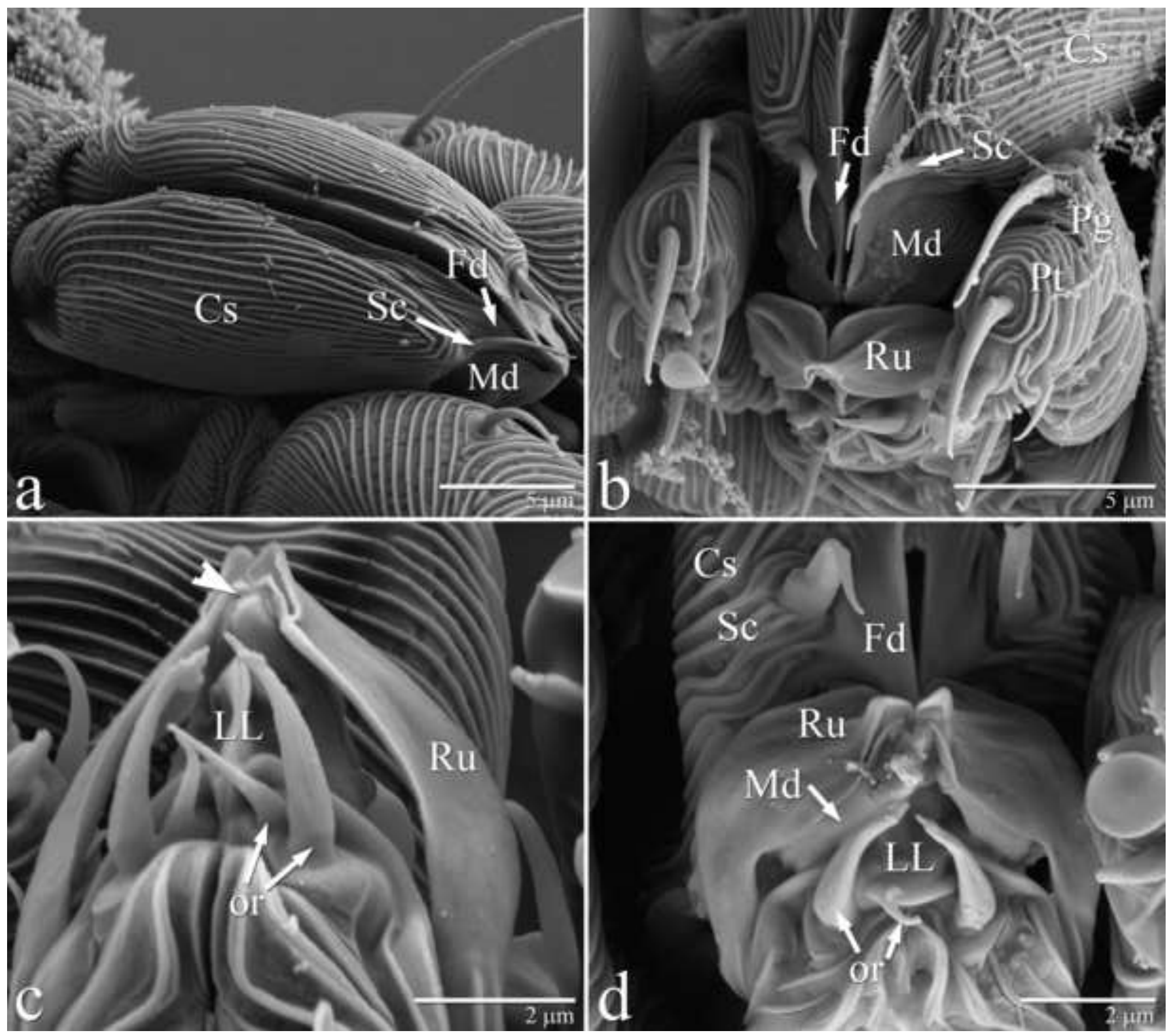

ง) $\iiint \int c /$
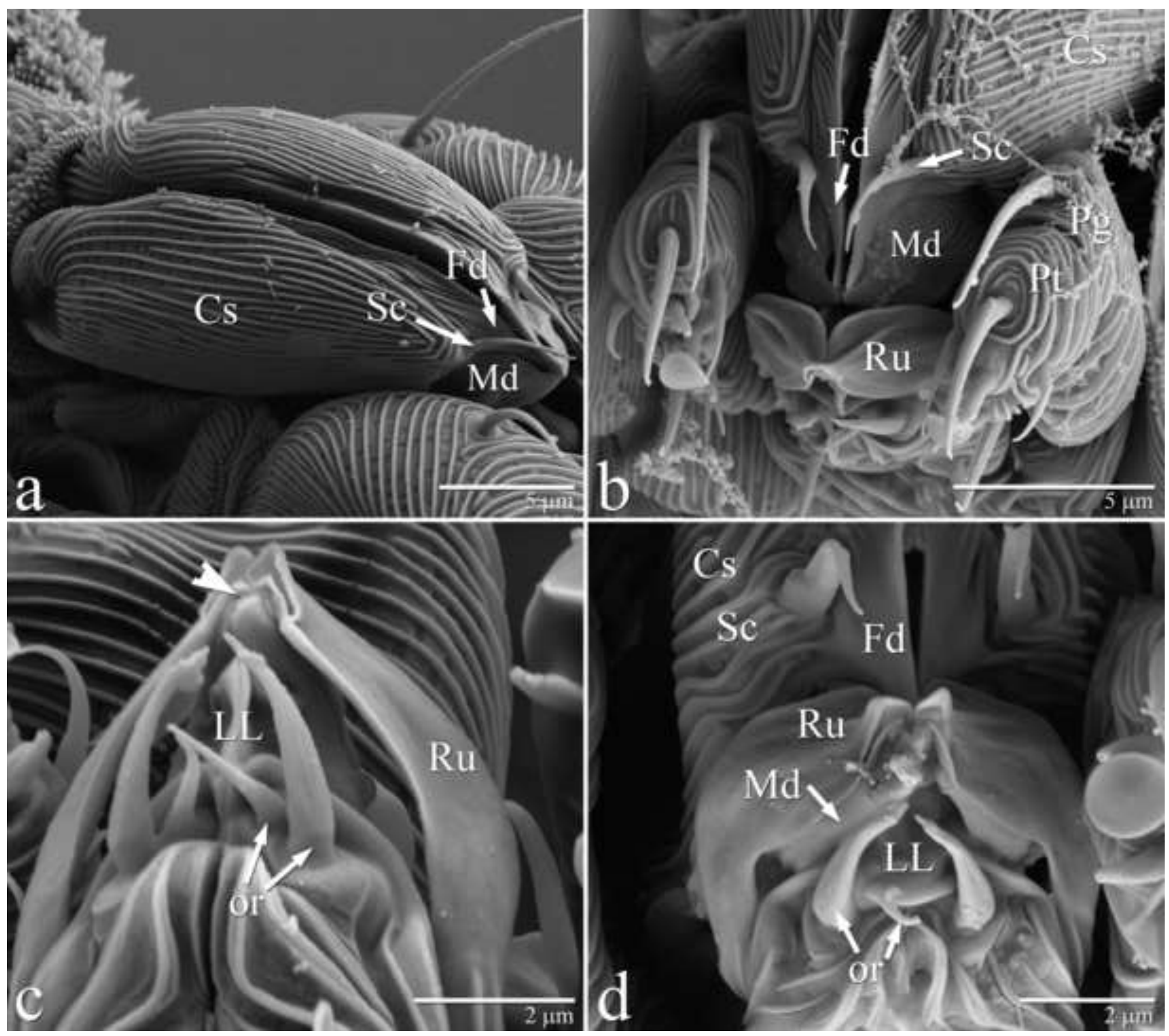


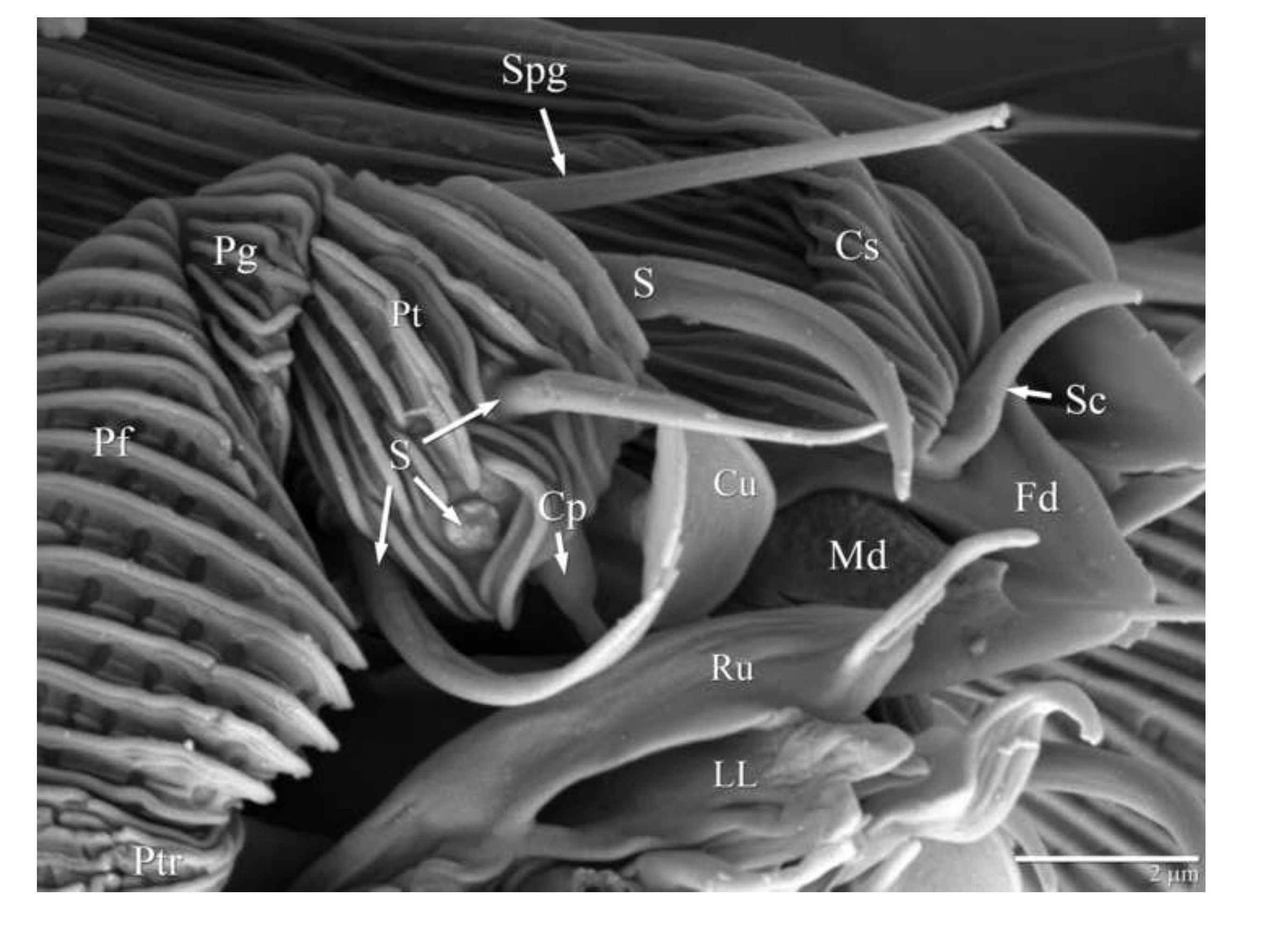

Spg
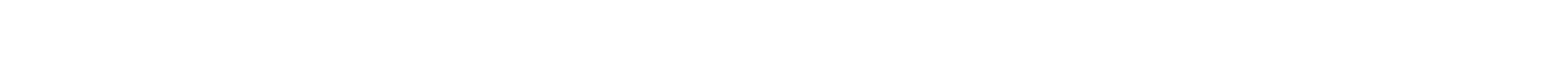